\title{
Pyridylsilyl Group as a Multifunctional Phase Tag for Solution-Phase Synthesis
}

\author{
Jun-ichi Yoshida* and Kenichiro Itami \\ Department of Synthetic Chemistry \& Biological Chemistry, Graduate School of \\ Engineering, Kyoto University,
}

Received July 5, 2001

\begin{abstract}
A novel phase tag strategy for the solution-phase synthesis, in which a 2-pyridyldimethylsilyl group functions as an efficient tag for acid/base extraction, is described. Various tagging and detagging protocols, and transformations using building blocks bearing the 2-pyridyldimethylsilyl group have been developed.
\end{abstract}

\section{Introduction}

The purpose of organic synthesis is to synthesize the desired compounds efficiently. Driven by remarkable improvements in understanding of the factors governing organic reactions, organic chemists have designed and developed a number of synthetically useful reactions so far, but the total efficiency and performance of synthetic transformations have been rather neglected. The efficiency of synthesis is often limited by the ability to separate and isolate the final product from the reaction mixture. Therefore, it should be noted that separation is a central issue in organic synthesis. In the 21 st century, reaction and separation should be greatly integrated to be more powerful tools for the synthesis of organic compounds. ${ }^{1,2}$

Although most organic reactions have been carried out in solution phase so far, solid phase has recently emerged as the medium of choice for the synthesis of chemical libraries. ${ }^{3}$ This is probably because of the key advantage of product isolation of solid-phase synthesis (Table 1). The product bound to insoluble polymer beads is separated from excess reagents and byproducts by simple filtration. However, solid-phase synthesis often suffers from disadvantages of low reactivity due to the heterogeneity of the media, limited reaction scale, limited reaction repertoire in the resin-bound media, difficulties in product analysis, and the high price of solid support (Table 1). On the other hand, solution-phase synthesis requires distillation or chromatography for purification, which is time-consuming and difficult to be automated.

Table 1. Advantages and disadvantages of solution-phase synthesis and solid-phase synthesis

\begin{tabular}{|c|c|c|}
\hline & Solution Phase & Solid Phase \\
\hline Reactivity & High & Low \\
\cline { 1 - 1 } Reaction Scale & Unlimited & Limited \\
\cline { 1 - 1 } Reaction Repertoire & Unlimited & Limited \\
\cline { 1 - 1 } Product Analysis & Easy & Difficult \\
\cline { 1 - 1 } Price & Low & High \\
\hline Separation \& Purification & Difficult & Easy \\
\cline { 1 - 2 } Automation & Difficult & Easy \\
\cline { 1 - 1 } Combinatorial Chemistry & Difficult & Easy \\
\hline
\end{tabular}

Therefore, the development of new solution-phase protocols having the advantages of easy separation like in solid-phase synthesis is strongly needed. In such protocols, a range of reactions can be conducted under homogeneous traditional conditions, yet the products can still be easily separated by a simple operation.

\section{Strategic Separation in Solution-Phase Synthesis}

Recently, several approaches have been studied to solve the difficulty in purifying compounds without sophisticated processes, and new strategy-level separations have been developed in solution-phase synthesis. For example, solid-supported reagents and catalysts have been developed enabling easy separation of products in solution from excess reagents and byproducts bound to an insoluble polymer by simple filtration. ${ }^{4}$ Microencapsulation, which utilizes a polymer to physically envelop, support, and immobilize a catalyst or a reagent, is also an intriguing approach for easy separation. ${ }^{5}$ In the polymeric scavenger approach, byproducts and excess reagents are selectively removed from solution via covalent bond formation to a solid-supported electrophile or nucleophile. ${ }^{6}$ Resin capture involves capture of a product, which is formed in solution-phase, on a resin followed by filtration to separate it from byproducts and release of the product back into solution. ${ }^{7}$ Sometimes, subsequent solid-phase transformations are carried on the resin before cleaving. Soluble polymer-supported synthesis (liquid phase synthesis) utilizes a polymer that is soluble in a variety of organic solvents for conducting a reaction in solution phase but can be precipitated out of the solution for purification purposes after a reaction. Polyethylene glycol polymers have been found to be effective for this purpose, because they have a strong propensity to crystallize in diethyl ether. ${ }^{8}$ Thermomorphic catalysts bound to a polymer can also be classified as this approach. ${ }^{9}$ Related to soluble polymer-supported synthesis, dendrimersupported chemistry has been developed, in which the purification is effected by size-based separation techniques such as size exclusion chromatography. ${ }^{10}$ In the fluorous synthesis approach, organic molecules are made soluble in fluorocarbon solvents by attaching a perfluorinated group so they can be easily separated from excess reagents and byproducts by the extraction with such solvents. ${ }^{11}$ The fluorous approach is also effective for separation and recovery of catalysts. ${ }^{12}$ Acid/base extraction is a traditional protocol of purification, 
but it has still high potentiality from the viewpoints of effectiveness, operation, safety, economy, and the environment. ${ }^{13,14}$

\section{Phase Tag Strategy}

In the stream of development of new solution-phase protocols for strategic separation, the concept of phase tag has appeared. ${ }^{1,15}$ Phase tag is a functional group that facilitates purification by phase separation such as liquid/liquid extraction, liquid/solid extraction, and filtration. A tag is introduced to a starting material before a transformation (tagging) and after the transformation is completed, the tag is removed from the product (detagging). Sometimes a reagent is tagged to enable easy separation from a product of natural phase affinity. The following points should be important factors in the design of tags for strategic separation: (1) easy tagging, (2) stability toward various reaction conditions, and (3) easy detagging under mild conditions.

\section{2-PyMe $\mathrm{Mi}_{2} \mathrm{Sroup}$ as a Phase Tag for Acid/Base Extraction}

Acid/base extraction (ABE) is quite effective for separation and purification of acidic or basic compounds. For example, basic compounds such as amines are purified as follows: The compound is first extracted to an acidic aqueous solution, because the ionic protonated form has strong propensity to dissolve in an aqueous phase. After the organic phase contaminated with other compounds to be removed is separated, the aqueous phase is neutralized and extracted with fresh organic solvent. In this operation the compound becomes a free base form, which is much less hydrophilic and thus has a strong propensity to dissolve in an organic phase. Therefore, the compound moves back to the organic phase. Similar ABE can also be conducted for purification of acidic compounds such as carboxylic acids, although the order of the use of acid and base is reversed.

The major disadvantage of ABE is that it can only be applied to compounds bearing an acidic or a basic functional group. In order to generalize $\mathrm{ABE}$ as a method for strategic separation and purification in solution-phase synthesis, we initiated a project on a tag for $\mathrm{ABE} .{ }^{16}$ As a first example of phase tags for $\mathrm{ABE}$ in our project, we designed a dimethyl(2pyridyl)silyl (2-PyMe $2 \mathrm{Si}$ ) group for the following reasons. (1) A pyridyl group is a basic group that tolerates various reaction conditions. (2) Carbon-silicon bonds are also rather stable under various reaction conditions. (3) There is a rich chemistry of organosilicon compounds. Therefore, we hoped that various methods would be available for the introduction and removal of the silyl group. (4) We also envisioned that the pyridyl group would assist metal-catalyzed or -promoted reactions by virtue of its strong coordinating ability (Figure 1).

\section{Acid/Base Phase Switching of 2-PyMe $\mathrm{MSi}_{2}$-Tagged Molecules}

In order to test the effectiveness of the $2-\mathrm{PyMe}_{2} \mathrm{Si}$ group as a phase tag, we first examined ABE of octyldimethyl(2pyridyl)silane (1) as a model compound (Figure 2). ${ }^{16}$ Acid extraction ( $1 \mathrm{~N} \mathrm{aq} \mathrm{HCl,} 6$ times) of a solution of 1 in $\mathrm{Et}_{2} \mathrm{O}$ transfers 1 to the aqueous phase. The neutralization of the aqueous phase $(\mathrm{pH}=\mathrm{ca} .7)$ followed by the extraction with $\mathrm{Et}_{2} \mathrm{O}$ (3 times) transfers 1 to the organic phase (98\% recovery). Therefore, the $2-\mathrm{PyMe}_{2} \mathrm{Si}$ group proved to be quite effective and efficient for the acid/base phase switching technique. ${ }^{17}$ It is also noteworthy that the $2-\mathrm{PyMe}_{2} \mathrm{Si}$ group is quite stable under both acidic and basic conditions.

\section{Removal of the 2-PyMe $\mathrm{Mi}_{2} \mathrm{Si}$ Group by Tamao Oxidation (Detagging)}

In a tag strategy, it is essential that the tag be removed from the final product. Otherwise, it cannot be used as a tag. Therefore, we first set out to establish a method for the removal of the $2-\mathrm{PyMe}_{2} \mathrm{Si}$ group (detagging). We were delighted to find that the $2-\mathrm{PyMe}_{2} \mathrm{Si}$ group was cleaved in a single step under the conditions of Tamao oxidation. ${ }^{18}$ For example, treatment of octyldimethyl(2-pyridyl)silane (1) with aq $30 \% \mathrm{H}_{2} \mathrm{O}_{2}$ (30 equiv) in the presence of $\mathrm{KF}$ ( 2 equiv) and $\mathrm{KHCO}_{3}$ (2 equiv) in THF/MeOH afforded 1-octanol in $82 \%$ yield. ${ }^{16,19}$ The presence of the 2-pyridyl group is essential for

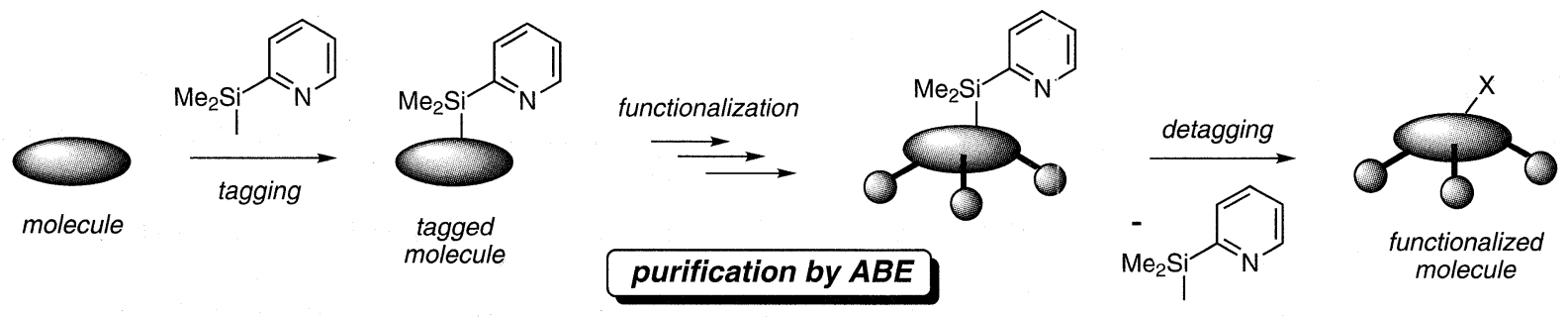

Figure 1. Synthetic strategy using $2-\mathrm{PyMe}_{2} \mathrm{Si}$ group as a phase tag.
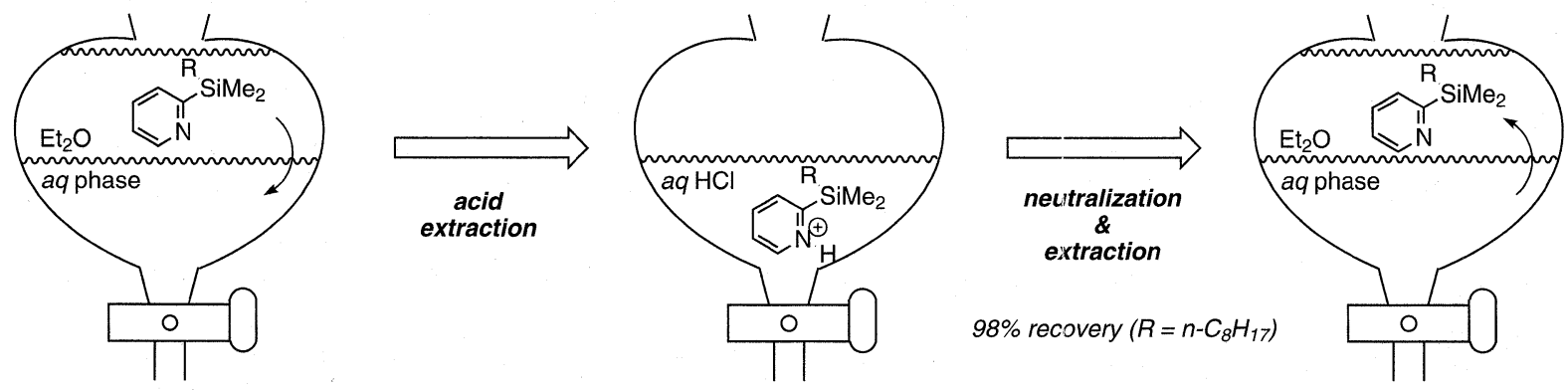

Figure 2. Acid/base phase switching technique using $2-\mathrm{PyMe}_{2} \mathrm{Si}$ group as a phase tag. 
this transformation, because neither octyldimethyl(3-pyridyl) silane nor octyldimethylphenylsilane gave 1-octanol under the same conditions. Mechanistic studies revealed that the $\mathrm{H}_{2} \mathrm{O}_{2}$ oxidation of the 2-PyMe $\mathrm{Pi}_{2} \mathrm{Si}$ group proceeds by the initial cleavage of the 2-Py-Si bond assisted by KF followed by the usual Tamao oxidation of the resulting methoxysilane (Scheme 1). ${ }^{19}$

\section{Scheme 1}

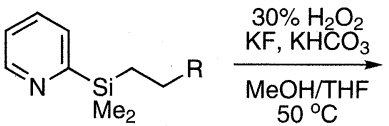

$$
\begin{aligned}
& {\left[\underset{\mathrm{Me}_{2}}{\mathrm{MeO}_{\mathrm{Si}}} \underset{\mathrm{R}}{\longrightarrow} \mathrm{HO}^{\mathrm{R}}\right.} \\
& \text { 2-Py-Si Cleavage } \Rightarrow \text { Tamao Oxidation }
\end{aligned}
$$

\section{Introduction of 2-PyMe $\mathrm{PSi}_{2} \mathrm{Group}$ by Hydrosilylation (Tagging)}

Because hydrosilylation reaction is an important method for making a carbon-silicon bond, we examined the introduction of the 2-PyMe $\mathrm{Pe}_{2} \mathrm{Si}$ group by hydrosilylation as a tagging protocol. ${ }^{16}$ For example, the rhodium-catalyzed hydrosilylation of alkenes with $2-\mathrm{PyMe}_{2} \mathrm{SiH}$ (2) proceeds smoothly to give the corresponding $2-\mathrm{PyMe}_{2} \mathrm{Si}$-tagged products in very high yield with virtually complete regioselectivity. The tagged product can be easily isolated in a pure form by simple $\mathrm{ABE}$ process (Scheme 2).

Interestingly, substantial rate-acceleration was observed with a pyridyl group on silicon. ${ }^{16}$ Under the identical conditions, other related hydrosilanes such as dimethylphenylsilane, dimethyl(3-pyridyl)silane, and dimethyl(4-pyridyl)silane were unreactive. $^{20}$ This implies that the coordination of the pyridyl group to the catalyst rhodium is very important for the reaction to occur under these very mild conditions $\left(28^{\circ} \mathrm{C}, 30\right.$ $\min )$.

\section{Scheme 2}

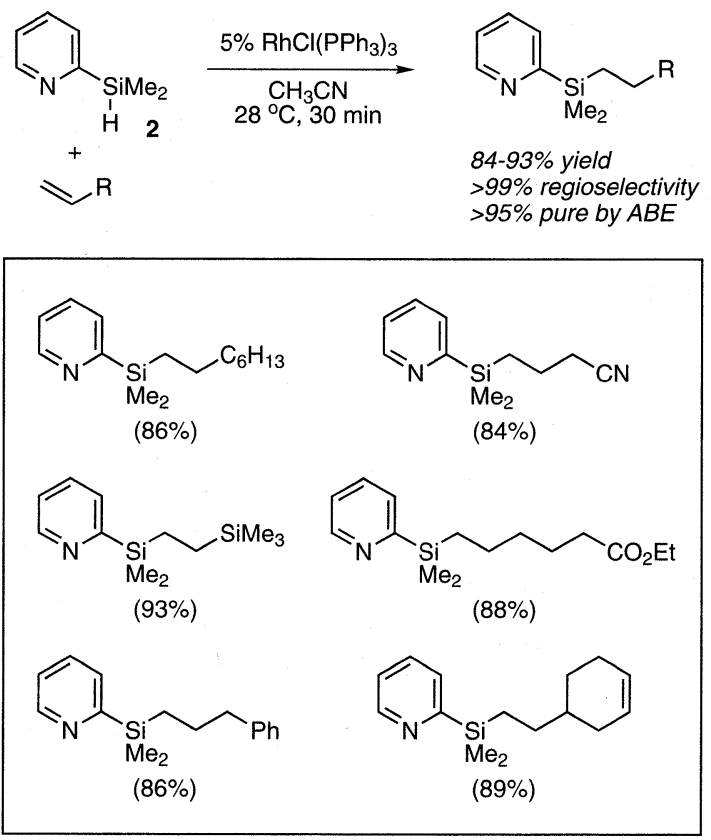

\section{Model Synthetic Transformation Using 2-PyMe $2 \mathrm{Si}$ Group as a Phase Tag}

To illustrate the utility of the 2-PyMe $\mathrm{Pe}_{2} \mathrm{Si}$ group as a phase tag in conventional and combinatorial solution-phase synthesis, we conducted a sequential multi-step transformation shown in Scheme 3. ${ }^{16}$ Methyl 3, 3-dimethyl-4-pentenoate was treated with 2 in the presence of $5 \mathrm{~mol} \%$ of $\mathrm{RhCl}\left(\mathrm{PPh}_{3}\right)_{3}$ in $\mathrm{CH}_{3} \mathrm{CN}$ at room temperature for $1 \mathrm{~h}$. Simple $\mathrm{ABE}$ afforded hydrosilylated product 3 in $83 \%$ yield with $>95 \%$ regioselectivity. In the next step, we carried out a model synthetic transformation in the presence of the $2-\mathrm{PyMe}_{2} \mathrm{Si}$ group as a tag. Thus, the 2-PyMe $\mathrm{Si}_{2}$-tagged compound 3 was treated with $\mathrm{MeLi}\left(5\right.$ equiv) in $\mathrm{Et}_{2} \mathrm{O}$ at $0{ }^{\circ} \mathrm{C}$ for $1 \mathrm{~h}$ to obtain tertiary alcohol 4 (93\% yield) which was purified by ABE. The products were quite pure (no identifiable starting materials or side products as judged by ${ }^{1} \mathrm{H}$ NMR and capillary GC analysis) and were used directly in the next step of the sequence. It is also noteworthy that satisfactory data of elemental analysis was obtained for 4 after simple ABE. In the final step, Tamao oxidation gave the corresponding diol 5 (detagged product) in $99 \%$ isolated yield. The success of this model transformation revealed that the silicon-based 2-PyMe ${ }_{2} \mathrm{Si}$ tag serves as a new efficient protocol for strategic separation and purification in solution-phase synthesis.

Scheme 3
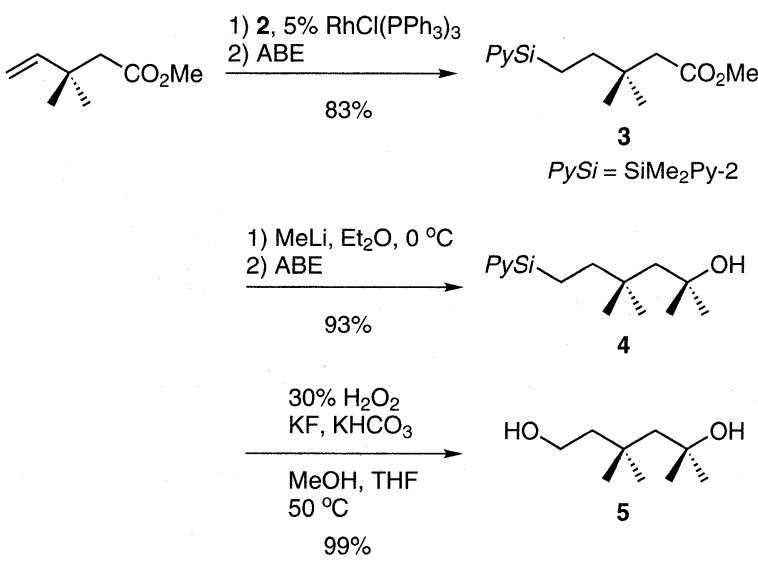

\section{2-Pyridyltrimethylsilane as a 2-PyMe 2 Si-Based Build- ing Block}

In the previous section, hydrosilylation is shown to serve as an efficient method for the introduction of the $2-\mathrm{PyMe}_{2} \mathrm{Si}$ group. Although this simple and straightforward tagging method is quite effective and useful, we have also been interested in methods using building blocks bearing the $2-\mathrm{PyMe}_{2} \mathrm{Si}$ group.

We have found that 2-pyridyltrimethylsilane (6) undergoes rapid deprotonation by basic treatment such as $t$-BuLi or lithium diisopropylamide (LDA) to generate (2-pyridyldimethylsilyl)methyllithium (2- $\mathrm{PyMe}_{2} \mathrm{SiCH}_{2} \mathrm{Li}$, 7) quantitatively (Scheme 4). ${ }^{21,22}$ It should be mentioned that a methyl group on silicon has been recognized as the most difficult group to deprotonate in silane deprotonation chemistry. Moreover, we have established that the deprotonation $\left(t-\mathrm{BuLi} / \mathrm{Et}_{2} \mathrm{O} /-78{ }^{\circ} \mathrm{C}\right)$ occurs with 6 but not with other related silanes such as phenyltrimethylsilane, 3-pyridyltrimethylsi- 
lane, and 4-pyridyltrimethylsilane. ${ }^{22}$ It seems that this deprotonation proceeded through the agency of the complexinduced proximity effect (CIPE) of a pyridyl group on silicon (Scheme 4). ${ }^{23}{ }^{1} \mathrm{H}$ NMR analysis of 7 revealed the intramolecular coordination of a pyridyl group to lithium.

Scheme 4
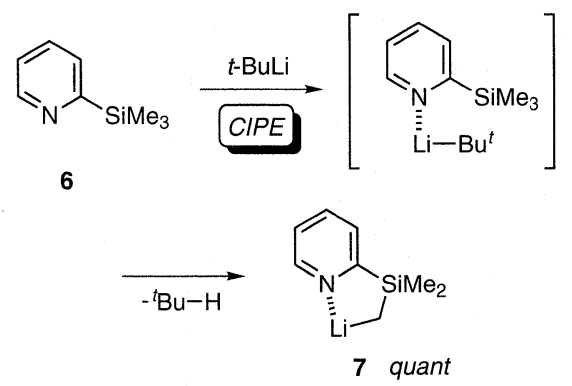

Organolithium compound 7 was found to react with various electrophiles to afford the 2-PyMe $\mathrm{Pi}_{2} \mathrm{Si}$-tagged products in good to excellent yields (Scheme 5). ${ }^{22,24}$ In almost all cases, the products were isolated in a pure form by the ABE purification process.

Scheme 5

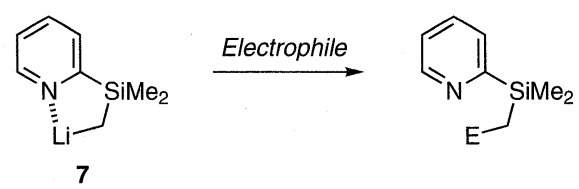

Electrophile (yield)

$\begin{array}{lll}\mathrm{Me}_{3} \mathrm{SiCl}(93 \%) & \mathrm{I}_{2}(84 \%) & \mathrm{PhCHO}(85 \%) \\ \mathrm{PhMe}_{2} \mathrm{SiCl}(99 \%) & \mathrm{CH}_{2}=\mathrm{CHCH}_{2} \mathrm{Br}(95 \%) & \mathrm{PhCH}_{2} \mathrm{CH}_{2} \mathrm{CHO}(63 \%) \\ \mathrm{Me}_{3} \mathrm{SnCl}(83 \%) & \mathrm{PhCH}_{2} \mathrm{Br}(99 \%) & \mathrm{CH}_{2}=\mathrm{CHCHO}(62 \%) \\ \mathrm{Bu}_{3} \mathrm{SnCl}(76 \%) & \mathrm{Ph}\left(\mathrm{CH}_{2}\right)_{3} \mathrm{Br}(84 \%) & \mathrm{PhC}(\mathrm{O}) \mathrm{Me}(55 \%) \\ \mathrm{Br}_{2}(65 \%) & \mathrm{Cl}\left(\mathrm{CH}_{2}\right)_{3} \mathrm{Br}(86 \%) & \text { cyclohexanone }(64 \%)\end{array}$

10. Bis(2-pyridyldimethylsilyl)methane as a $2-\mathrm{PyMe}_{2} \mathrm{Si}-$ Based Building Block

Related to the silylmethyllithium reagent 7 described in the previous section, appending one more $2-\mathrm{PyMe}_{2} \mathrm{Si}$ group was found to be interesting. The starting material bis(2-pyridyldimethylsilyl)methane (8) can be easily prepared by the reaction of 7 with 2 -pyridyldimethylsilane (2). ${ }^{22}$ The corresponding bis(silyl)methyllithium (2-PyMe $\mathrm{Si}_{2} \mathrm{SiLi}$ (9) was found to be easily generated by the deprotonation of 8 using $n^{-}$ BuLi. $^{25,26}$ The coordination of two pyridyl groups to lithium was ascertained by the low-temperature ${ }^{1} \mathrm{H}$ NMR spectroscopy of 9 in $\mathrm{Et}_{2} \mathrm{O}-d_{10}$ (Scheme 6).

Bis(silyl)methyllithium 9 was found to react with various carbonyl compounds giving the corresponding alkenylsilanes by the well-known Peterson-type elimination process (Scheme 6). ${ }^{25,26}$ In all cases, virtually complete stereoselectivity $(>99 \% E)$ was observed.

It has been well documented that the acid- or base-mediated elimination from the isolated $\beta$-silyl alcohol is highly stereoselective. ${ }^{27}$ However, this is not the case for the direct addition/elimination sequences especially when bis(silyl) methyllithium reagents are employed. ${ }^{27}$ To the best of our knowledge, this is the first general method for the stereoselective synthesis of alkenylsilane, which proceeds with direct addition/elimination sequences. The beneficial effect (most
Scheme 6

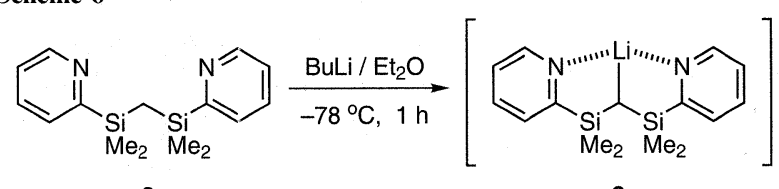

8

9
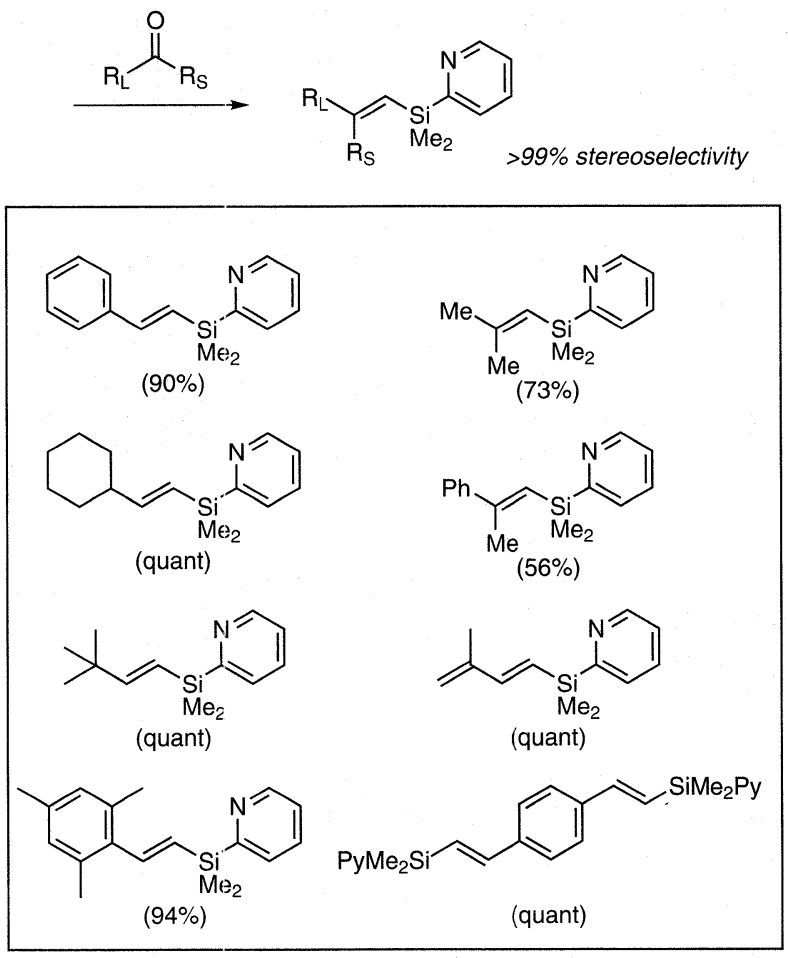

likely the coordination effect) of the pyridyl group has been highly implicated.

\section{Alkenyldimethyl(2-pyridyl)silanes as $2-\mathrm{PyMe}_{2} \mathrm{Si}$-Based Building Blocks}

Alkenyldimethyl(2-pyridyl)silanes also serves as useful building blocks bearing the $2-\mathrm{PyMe}_{2} \mathrm{Si}$ group. Alkenyldimethyl(2-pyridyl)silanes are readily prepared by hydrosilylation of alkynes with $2 .^{20}$ Peterson olefination of carbonyl compounds with 9 is also effective to prepare alkenyldimethyl (2-pyridyl)silanes stereoselectively. ${ }^{25,26}$

\subsection{Carbomagnesation}

The addition of organolithium reagents to alkenylsilanes is a powerful method for the generation of synthetically useful $\alpha$-silyl carbanions. Although Grignard reagents are a viable alternative for this addition reaction, serious limitations are associated with the carbomagnesation methodology: (1) Activating groups on silicon (e.g., choloro, alkoxy, and amino groups) are needed for the addition (no reaction with trialkyl(alkenyl)silanes); (2) substitution at the silicon atom is often observed as an unavoidable side reaction when these activating groups are used; and (3) primary alkyl Grignard reagents are not applicable in the reaction. These drawbacks greatly diminish the synthetic usefulness of this otherwise attractive methodology.

During the course of our investigation, we have found that various Grignard reagents, including primary alkyl Grignard reagent, add across alkenyldimethyl(2-pyridyl)silanes (10) under extremely mild conditions. ${ }^{28}$ We assume that this carbomagnesation was facilitated by CIPE (Scheme 7). The 
reaction presumably involves a pre-equilibrium complex of 10 and $\mathrm{RMgX}$, rendering the subsequent carbomagnesation event intramolecular in nature. The importance of this preequilibrium complex formation was further supported by the observation of dramatic solvent effects; weakly coordinating solvents such as $\mathrm{Et}_{2} \mathrm{O}$ favor this reaction whereas strongly coordinating solvents such as THF disfavor the reaction. These results may be attributed to the inhibition of pre-equilibrium complex formation by the coordinating solvent. In addition to this kinetic preference, we presume that the stabilization of the generated $\alpha$-silyl organomagnesium compound by the intramolecular pyridyl group coordination is also responsible for the efficiency of this carbomagnesation process.

Moreover, the thus-generated $\alpha$-silyl organomagnesium compounds were allowed to react with various electrophiles such as organic halides and carbonyl compounds (Scheme 7). ${ }^{28}$ It is also interesting that aryl and heteroaryl halides can be used as electrophiles by utilizing $\mathrm{Pd}\left(\mathrm{PPh}_{3}\right)_{4}$ as catalyst. Thus, this novel three-component coupling reaction proved to be an efficient protocol for the $2-\mathrm{PyMe}_{2} \mathrm{Si}$ group-tagging protocol.

\section{Scheme 7}
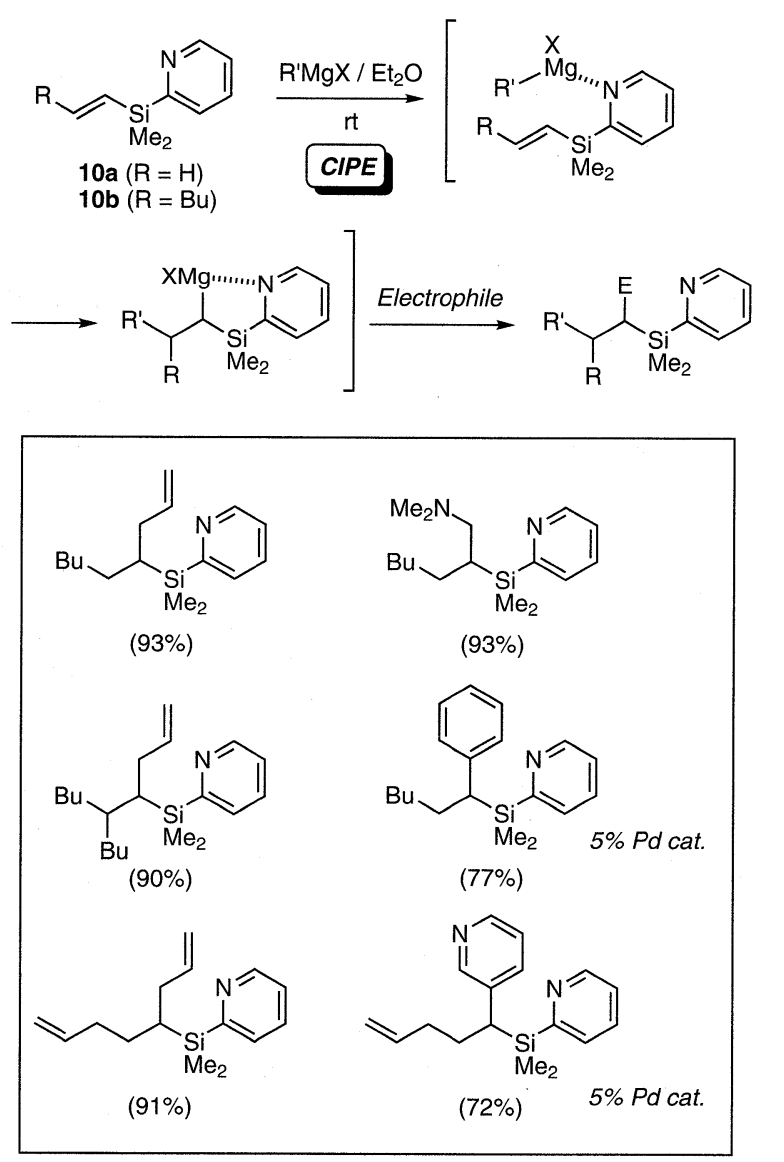

\subsection{Palladium-Catalyzed Heck-type Coupling}

The palladium-catalyzed Heck-type coupling ${ }^{29}$ of alkenyldimethyl(2-pyridyl)silanes (10) occurs under very mild conditions (Scheme 8) ${ }^{30}$ It is reasonable to consider that the realization of the previously difficult Heck-type coupling stems from the efficient carbopalladation based on CIPE as observed in the carbomagnesation of $\mathbf{1 0}$ (Scheme 7). ${ }^{28}$
It already has been known that there are several difficulties in the Heck-type coupling of alkenylsilane. For example, the treatment of alkenylsilane with aryl iodide under the typical Heck reaction conditions affords exclusively a styrene derivative as a result of carbon-silicon bond cleavage. ${ }^{31}$ Generally, the Heck-type coupling of alkenylsilane requires the addition of an equimolar amount of silver nitrate. ${ }^{32}$

Noteworthy features of the present process are that (1) the carbon-silicon bond cleavage was completely suppressed even in the absence of a silver salt, (2) the coupling occurred under mild conditions $\left(50{ }^{\circ} \mathrm{C}\right.$ ) and at low catalyst loading (as low as $0.1 \mathrm{~mol} \%$ ), (3) virtually complete stereoselectivity (>99\% $E$ ) was observed in all cases examined, and (4) the regio- and stereoselective coupling occurred even with the alkenylsilanes bearing a substituent at the $\beta$ position such as $\mathbf{1 0 b}$.

Scheme 8
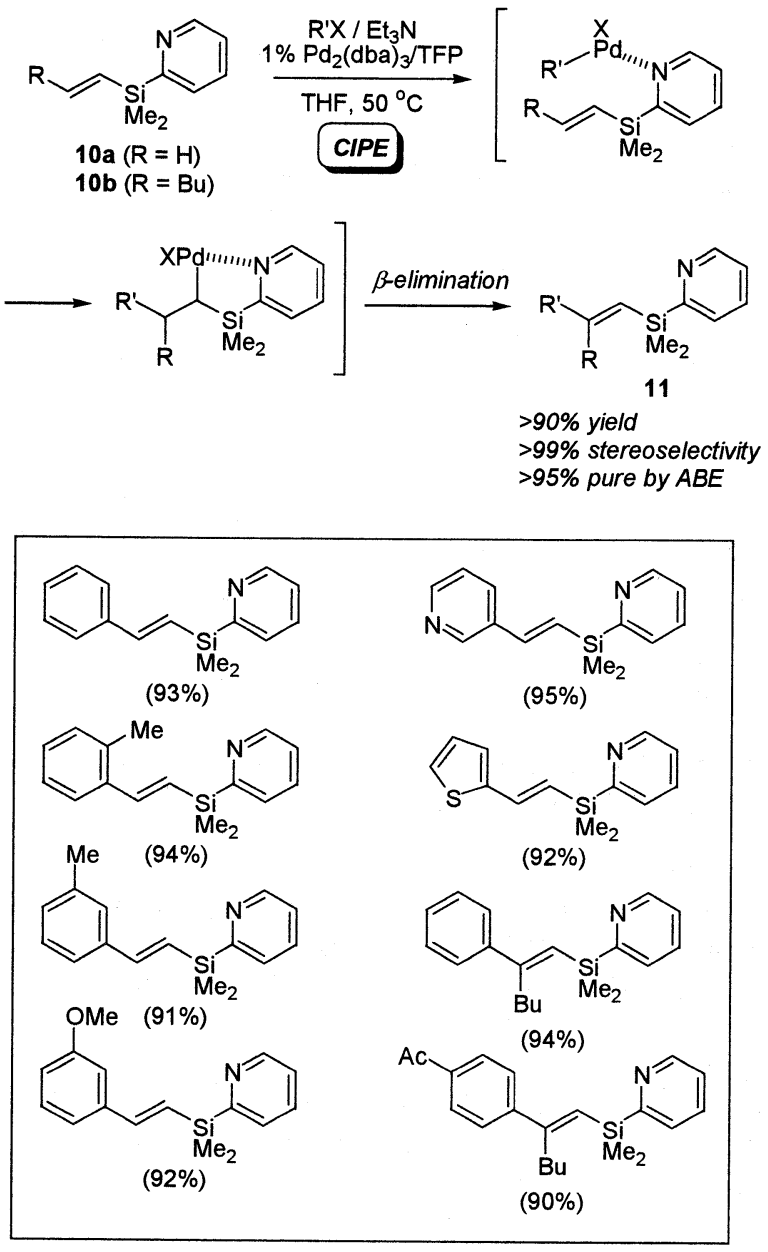

By taking advantage of the phase tag property of the 2$\mathrm{PyMe}_{2} \mathrm{Si}$ group, all products listed in Scheme 8 were isolated by $\mathrm{ABE}$ (Figure 3). The yield of $\mathbf{1 1}$ using this $\mathrm{ABE}$ is generally higher $(\sim 5 \%)$ than that using silica gel chromatography and is slightly lower than that determined by GC analysis of the reaction mixture. Importantly, the purities of $\mathbf{1 1}$ are over $95 \%$ in all cases as judged by NMR and GC analysis.

Another interesting aspect in this ABE process is that the palladium catalyst can be easily recovered from the initial organic phase (Figure 3). The recovery of the palladium catalyst was almost quantitative so that the catalyst may be used for the next reaction. Indeed, the thus-recovered catalyst can 


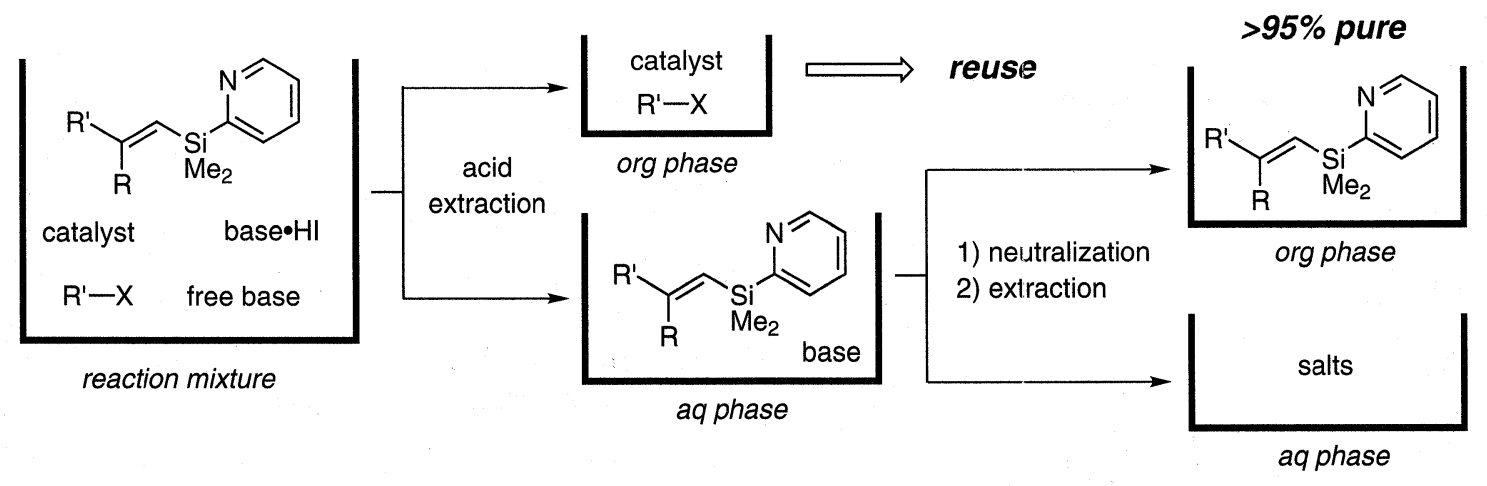

Figure 3. Acid/base extraction process for the purification of coupling product and the recovery of palladium catalyst.

Scheme 9

Heck-type Coupling

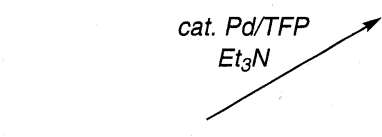

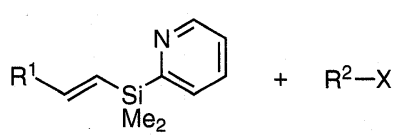

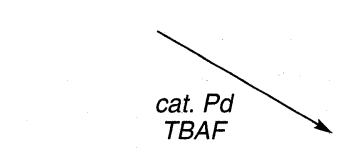

Hiyama-type Coupling

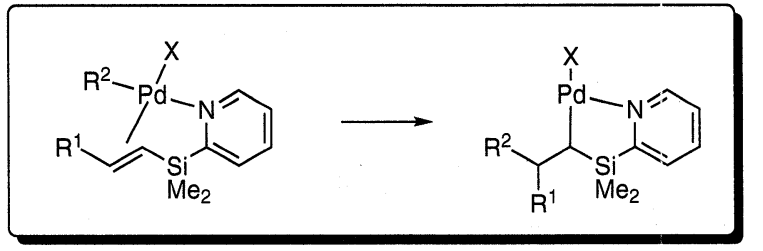

Coordination-Driven Carbopalladation<smiles>[R]C([R])=C[Si](C)(C)c1ccccn1</smiles>

$\longrightarrow \mathrm{R}^{1} \leadsto \mathrm{R}^{2}$

\section{C-Si Bond Cleavage}

be used several times without any significant loss of catalytic activity and stereoselectivity. This implies that the recovery of the metal catalyst does not necessarily have to rely on the polymer-supported catalyst, and clearly paves the way for the strategic catalyst recovery in the solution-phase synthesis.

\subsection{Palladium-Catalyzed Hiyama-type Coupling}

In the previous section we have shown that Tamao oxidation serves as an effective method for detagging of alkyldimethyl(2-pyridyl)silanes. In this section we demonstrate that the palladium-catalyzed Hiyama-type coupling ${ }^{33}$ could be used as a detagging protocol for alkenyldimethyl(2-pyridyl)silanes. ${ }^{34}$ Although Heck-type coupling of alkenyldimethyl(2-pyridyl) silanes occurs with aryl iodides in the presence of $\operatorname{Pd}_{2}(\mathrm{dba})_{3} /$ tri-2-furylphosphine (TFP) catalyst and triethylamine, ${ }^{30}$ the palladium-catalyzed Hiyama-type coupling exclusively takes place in the presence of tetrabutylammonium fluoride (TBAF) giving the olefins in very high yields (Scheme 9). ${ }^{34}$

Mechanistic studies revealed that the pyridyl group on silicon was selectively removed by the action of TBAF to produce the corresponding silanol ${ }^{35}$ in situ (Scheme 9). It may be plausibly deduced that the perfect switch of the reaction course (Heck-type coupling vs Hiyama-type coupling) stems from the selective removal of the Heck-coupling-directing pyridyl group and the introduction of an electronegative group that activates silicon as a leaving group.

With the selective detagging protocol in hand, a survey of the substrate scope was undertaken (Scheme 10). Various
Scheme 10
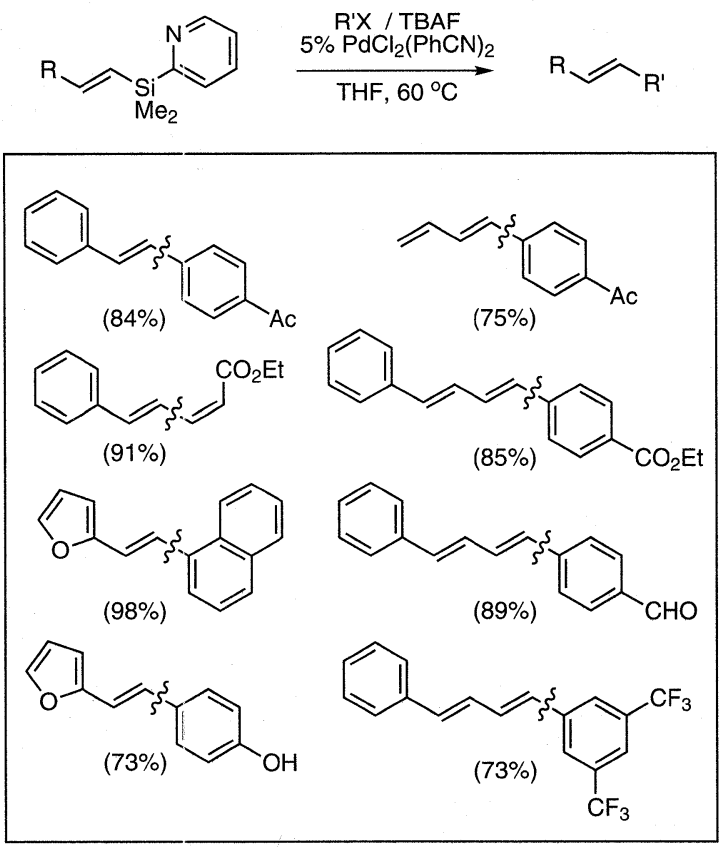

electronically and structurally diverse aryl and alkenyl halides were found to cross-couple with alkenyldimethyl(2-pyridyl) silanes giving the stereo-defined olefins in good to excellent yields. 


\section{Scheme 11}
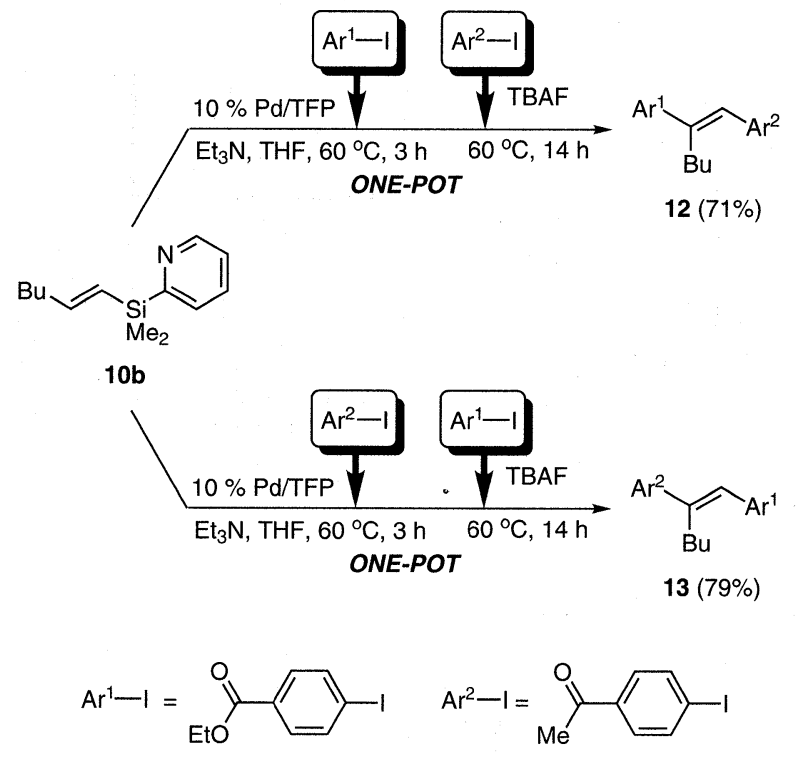

In light of the ability of alkenyldimethyl(2-pyridyl)silane to cross-couple with organic halide in two mechanistically different modes, we next embarked on a one-pot sequential cross-coupling, in which the Heck-type coupling occurs first and the Hiyama-type coupling takes place thereafter (Scheme 11). ${ }^{34}$ The alkenylsilane 10b was initially cross-coupled with aryl iodide in the presence of Pd/TFP catalyst. After the initial reaction completed, another aryl iodide and TBAF were added to the mixture to obtain cross-coupling product 12 in $71 \%$ yield. Interestingly, the regioisomer 13 can be obtained in $79 \%$ yield by simply changing the order of addition. In both cases, the reaction proceeded in virtually complete regioand stereoselective fashion.

\subsection{Reaction with Electrophiles}

As well as the Hiyama-type coupling, the electrophilic cleavage of alkenyldimethyl(2-pyridyl)silane can also be used as a $2-\mathrm{PyMe}_{2} \mathrm{Si}$-detagging protocol..$^{25,26,30}$ For example, treatment of alkenyldimethyl(2-pyridyl)silane with acetyl chloride in the presence of $\mathrm{AlCl}_{3}$ afforded the corresponding $\alpha, \beta$ unsaturated ketone (Scheme 12). Bromination of alkenyl dimethyl(2-pyridyl)silane afforded alkenyl bromide (Scheme 12).

Scheme 12

$$
\begin{aligned}
& \underbrace{R}_{R^{\prime}} \prod_{O}^{R^{\prime \prime}} \\
& \uparrow \mathrm{R}^{\mathrm{AlCOCl}} \mathrm{AlCl}_{3}
\end{aligned}
$$

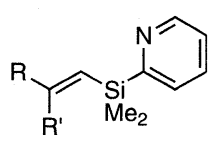

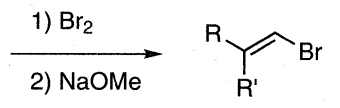

$$
\begin{aligned}
& \mid \begin{array}{c}
\mathrm{KF} / \mathrm{KHCO}_{3} \\
\mathrm{MeOH} / \mathrm{THF} \\
50^{\circ} \mathrm{C}, 2 \mathrm{~h}
\end{array} \\
& \mathrm{R}_{\mathrm{R}^{\prime}}^{\mathrm{R}} \underset{\mathrm{Sil}^{-}}{\mathrm{OMMe}}
\end{aligned}
$$

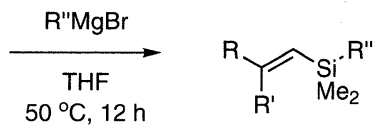

Alternatively, alkenyldimethyl(2-pyridyl)silane can be converted to other alkenylsilane as well (Scheme 12). ${ }^{25,26,30} \mathrm{Sub}$ jection of alkenyldimethyl(2-pyridyl)silane to the action of $\mathrm{KF} / \mathrm{MeOH}$ led to the formation of alkenyldimethyl(methoxy) silane by $2-\mathrm{Py}-\mathrm{Si}$ bond cleavage. The resultant methoxysilane can be further allowed to react with Grignard reagents to give the corresponding alkenyltrialkylsilane that can be used for further transformation.

\section{Other 2-PyMe $\mathrm{Mi}_{2} \mathrm{Si}$ Group-Assisted Reactions (Palladi- um-Catalyzed Allylic Alkylation)}

As mentioned, we established that the $2-\mathrm{PyMe}_{2} \mathrm{Si}$ group functions not only as a phase tag but also as an excellent directing group in various metal-catalyzed and -mediated reactions. In ongoing efforts to exploit this group for the metal-catalyzed reactions, we discovered that the $2-\mathrm{PyMe}_{2} \mathrm{Si}$ group effectively directs the alkylation site in the palladiumcatalyzed allylic alkylation. ${ }^{36}$

Palladium-catalyzed allylic alkylation of 2-PyMe ${ }_{2} \mathrm{Si}$-substituted allylic acetates 14 and $\mathrm{NaCH}\left(\mathrm{CO}_{2} \mathrm{Et}\right)_{2}$ predominantly produced 15 (95\% regioselectivity) as the result of a nucleophilic attack at the more substituted carbon of the allylic moiety (Scheme 13). This unusual inner site-selective allylic alkylation was found to be a general phenomenon for the stabilized soft carbon nucleophiles. Quite interestingly, the use of an organotin compound as a nucleophile, on the other hand, gave rise to a complete switch of the regioselectivity of the reaction, in which the nucleophilic attack occurred at the allylic terminus remote from the silyl group (Scheme 13). To the best of our knowledge, such a regioselectivity switch has not been observed in ( $\pi$-allyl)palladium chemistry. Mechanistic studies revealed that the coordination of the pyridyl group to the catalyst palladium has a decisive influence on the observed regioselectivity.

Scheme 13

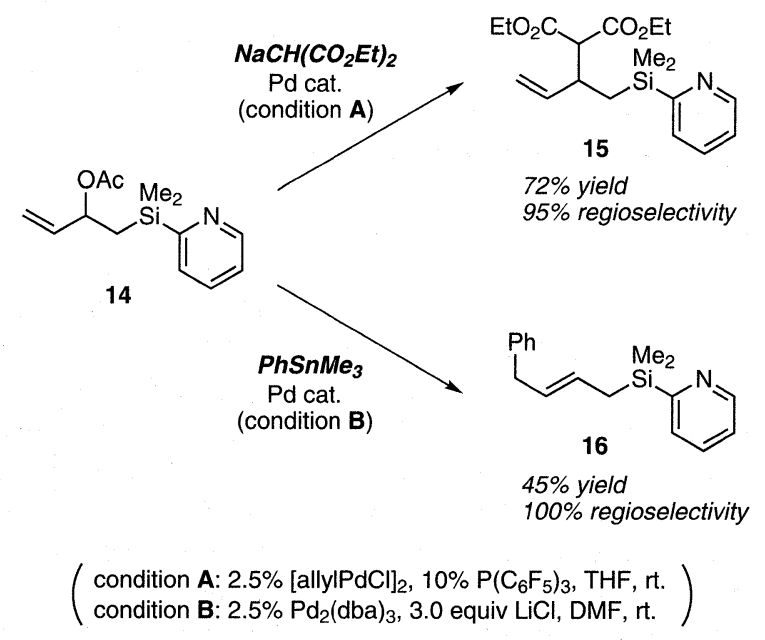

\section{Conclusion}

In conclusion, we have developed the $2-\mathrm{PyMe}_{2} \mathrm{Si}$ group as a multifunctional phase tag for solution-phase synthesis. As for a method for tagging, hydrosilylation with $2-\mathrm{PyMe}_{2} \mathrm{SiH}$ has been developed. We have also developed several building blocks bearing the 2-PyMe $\mathrm{Pe}_{2} \mathrm{Si}$ group, and their reactions were facilitated by the strong coordination ability of the pyridyl group. Moreover, detagging protocols such as Tamao- 
Fleming-type oxidation, Hiyama-type coupling, and electrophilic desilylation have also been developed. There should be many possibilities for the use of a 2-pyridylsilyl group in organic synthesis as a multifunctional phase tag. We are currently working to realize such possibilities.

Acknowledgment We are grateful to our co-workers, Mr. Koichi Mitsudo, Mr. Toshiki Nokami, Mr. Tooru Koike, Mr. Toshiyuki Kamei, Mr. Yoji Ishimura, and Mr. Akira Nishino for their excellent collaboration. This research was supported by a Grant-in-Aid for Scientific Research from the Ministry of Education, Science, Sports, and Culture, Japan, and the Mitsubishi Foundation. K.I. thanks Nissan Chemical Industries for the Award in Synthetic Organic Chemistry, Japan.

\section{References}

1) Curran, D. P. Angew. Chem., Int. Ed. 1998, 37, 1174.

2) (a) Baker, R. T.; Tumas, W. Science 1999, 284, 1477. (b) Ripka, W. C.; Barker, G.; Krakover, J. Drug Discovery Today 2001, 6, 471.

3) (a) Terrett, N. K.; Gardner, M.; Gordon, D. W.; Kobylecki, R. J.; Steele, J. Tetrahedron 1995, 51, 8135. (b) Balkenhohl, F.; von dem Bussche-Hünnefeld, C.; Lansky, A.; Zechel, C. Angew. Chem., Int. Ed. Engl. 1996, 35, 2288.

4) (a) Ley, S. V.; Baxendale, I. R.; Bream, R. N.; Jackson, P. S.; Leach, A. G.; Longbottom, D. A.; Nesi, M.; Scott, J. S.; Storer, R. I.; Taylor, S. J. J. Chem. Soc., Perkin Trans. 1 2000, 3815. (b) Kirschning, A.; Monenschein, H.; Wittenberg, R. Angew. Chem., Int. Ed. 2001, 40, 650.

5) (a) Kobayashi, S.; Nagayama, S. J. Am. Chem. Soc. 1998, 120 2985. (b) Kobayashi, S.; Endo, M.; Nagayama, S. J. Am. Chem. Soc. 1999, 121, 11229

6) (a) Kaldor, S. W.; Siegel, M. G.; Fritz, J. E.; Dressman, B. A.; Hahn, P. J. Tetrahedron Lett. 1996, 37, 7193. (b) Eames, J.; Watkinson, M. Eur. J. Org. Chem. 2001, 1213.

7) Keating, T. A.; Armstrong, R. W. J. Am. Chem. Soc. 1996, 118 , 2574

8) Toy, P. H.; Janda, K. D. Acc. Chem. Res. 2000, 33, 546.

9) Bergbreiter, D. E.; Osburn, P. L.; Wilson, A.; Sink, E. M. J. Am. Chem. Soc. 2000, 122, 9058.

10) (a) Kim, R. M.; Manna, M.; Hutchins, S. M.; Griffin, P. R.; Yates, N. A.; Bernick, A. M.; Chapman, K. T. Proc. Natl. Acad. Sci. USA 1996, 93, 10012. (b) Hovestad, N. J.; Ford, A.; Jastrzebski, J. T. B. H.; van Koten, G. J. Org. Chem. 2000, 65, 6338.

11) (a) Studer, A.; Hadida, S.; Ferritto, R.; Kim, S. Y.; Jeger, P.; Wipf, P.; Curran, D. P. Science 1997, 275, 823. (b) Ryu, I.; Niguma, T.; Minakata, S.; Komatsu, M.; Luo, Z.; Curran, D. P. Tetrahedron Lett. 1999, 40, 2367. (c) Luo, Z.; Zhang, Q.; Oderaotoshi, Y.; Curran, D. P. Science 2001, $291,1766$.

12) (a) Horváth, I. T.; Rábai, J. Science 1994, 266, 72. (b) Horváth, I. T. Acc. Chem. Res. 1998, 31, 641. (c) Barthel-Rosa, L. P.; Gladysz, J. A. Coord. Chem. Rev. 1999, 192, 587. (d) de Wolf, E.; van Koten, G.; Deelman, B. J. Chem. Soc. Rev. 1999, 28, 37. (e) Koch, D.; Leitner, W. J. Am. Chem. Soc. 1998, 120, 13398. (f) Nakamura, Y.; Takeuchi, S.; Ohgo, Y.; Curran, D. P. Tetrahe- dron Lett. 2000, 41, 57. (g) Betzemeier, B.; Cavazzini, M.; Quici, S.; Knochel, P. Tetrahedron Lett. 2000, 41, 4343. (h) Bergbreiter, D. E.; Franchina, J. G.; Case, B. L.; Org. Lett. 2000, $2,393$.

13) Boger, D. L.; Chai, W.; Jin, Q. J. Am. Chem. Soc. 1998, 120, 7220.

14) Perrier, H.; Labelle, M. J. Org. Chem. 1999, 64, 2110

15) (a) Ramage, R.; Swenson, H. R.; Shaw, K. T. Tetrahedron Lett. 1998, 39, 8715. (b) Hay, A. M.; Hobbs-Dewitt, S.; MacDonald, A. A.; Ramage, R. Tetrahedron Lett. 1998, 39, 8721. (c) Zhang, S.; Fukase, K.; Kusumoto, S. Tetrahedron Lett. 1999, 40, 7479. (d) Wang, X.; Parlow, J. J.; Proco, Jr., J. A. Org. Lett. 2000, 2, 3509. (e) Ley, S. V.; Massi, A.; Rodríguez, F.; Horwell, D. C.; Lewthwaite, R. A.; Pritchard, M. C.; Reid, A. M. Angew. Chem., Int. Ed. 2001, 40, 1053. (f) Bosanac, T.; Yang, J.; Wilcox, C. S. Angew. Chem. Int. Ed. 2001, 40, 1875.

16) Yoshida, J.; Itami, K.; Mitsudo, K.; Suga, S. Tetrahedron Lett. 1999, 40, 3403.

17) For the use of the 2-PyMe $\mathrm{Me}_{2} \mathrm{Si}$ group as a removable hydrophilic group in aqueous organic reaction, see: Itami, K.; Nokami, T.; Yoshida, J. Angew. Chem., Int. Ed. 2001, 40, 1074.

18) (a) Tamao, K. In Advances in Silicon Chemistry; Larson, G. L., Ed.; JAI Press Inc., 1996; Vol. 3, pp 1-62. (b) Fleming, I. Chem Tracts: Org. Chem. 1996, 1. (c) Jones, G. R.; Landais, Y. Tetrahedron 1996, 52, 7599.

19) Itami, K.; Mitsudo, K.; Yoshida, J. J. Org. Chem. 1999, 64, 8709.

20) Itami, K.; Mitsudo, K.; Nishino, A.; Yoshida, J., unpublished results.

21) Itami, K.; Mitsudo, K.; Yoshida, J. Tetrahedron Lett. 1999, 40, 5533.

22) Itami, K.; Kamei, T.; Mitsudo, K.; Nokami, T.; Yoshida, J. J. Org Chem 2001, 66, 3970.

23) For reviews on CIPE, see: (a) Beak, P.; Meyers, A. I. Acc. Chem. Res. 1986, 19, 356. (b) Hoveyda, A. H.; Evans, D. A.; Fu, G. C. Chem. Rev. 1993, 93, 1307.

24) Itami, K.; Mitsudo, K.; Yoshida, J. Tetrahedron Lett. 1999, 40, 5537

25) Itami, K.; Nokami, T.; Yoshida, J. Org. Lett. 2000, 2, 1299.

26) Itami, K.; Nokami, T.; Yoshida, J. Tetrahedron 2001, 57, 5045.

27) Hudrlik, P. F.; Agwaramgbo, E. L. O.; Hudrlik, A. M. J. Org. Chem. 1989, 54, 5613.

28) Itami, K.; Mitsudo, K.; Yoshida, J. Angew. Chem., Int. Ed. 2001, 40, 2337.

29) Beletskaya, I. P.; Cheprakov, A. V. Chem. Rev. 2000, 100, 3009.

30) Itami, K.; Mitsudo, K.; Kamei, T.; Koike, T.; Nokami, T.; Yoshida, J. J. Am. Chem. Soc. 2000, 122, 12013.

31) Hallberg, A.; Westerlund, C. Chem. Lett. 1982, 1993.

32) (a) Daves, G. D., Jr.; Hallberg, A. Chem. Rev. 1989, 89, 1433. See also: (b) Yamashita, H.; Roan, B. L.; Tanaka, M. Chem. Lett. 1990, 2175. (c) Jeffery, T. Tetrahedron Lett. 1999, 40, 1673.

33) Hiyama, T. In Metal-Catalyzed Cross-Coupling Reactions; Diederich, F.; Stang, P. J., Eds.; Wiley-VCH: Weinheim, 1998, pp 421-453.

34) Itami, K.; Nokami, T.; Yoshida, J. J. Am. Chem. Soc. 2001, 123, 5600 .

35) (a) Hirabayashi, K.; Mori, A.; Kawashima, J.; Suguro, M.; Nishihara, Y.; Hiyama, T. J. Org. Chem. 2000, 65, 5342. (b) Denmark, S. E.; Wehrli, D. Org. Lett. 2000, 2, 565.

36) Itami, K.; Koike, T.; Yoshida, J. J. Am. Chem. Soc. 2001, 123, 6957. 


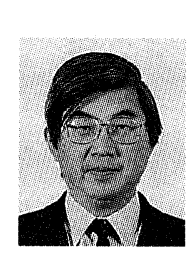

Jun-ichi Yoshida is a Professor of Kyoto University. He was born in Osaka, Japan, in 1952. He received his $\mathrm{Ph}$. D. from Kyoto University under the direction of Professor Makoto Kumada in 1981. He became an assistant professor of Kyoto Institute of Technology in 1979, an assistant professor of Osaka City University in 1985, an associate professor of Osaka City University in 1992, and a full professor of Kyoto University in 1994. He worked with Professor B. M. Trost, University of Wisconsin, for one year from 1982 as a postdoctral fellow. He received the Progress Award of Synthetic Organic Chemistry, Japan in 1987 and the Award of the Chemical Society of Japan (Gakujutsu-sho) in 2001. His current research interests are integrated synthesis, synthetic methodology, electroorganic chemistry, organometallic chemistry, computational chemistry, and automated synthesis.

Kenichiro Itami is an Assistant Professor of Kyoto University. He was born in Pittsburgh (Pennsylvania, USA) in 1971. He received his $\mathrm{Ph}$. D. in 1998 from Kyoto University under the supervision of Professor Yoshihiko Ito. During that time he joined Professor Jan E. Bäckvall's group at Uppsala University and Stockholm University (Sweden) as a visiting researcher (1997-1998). In 1998, he became an assistant professor of Kyoto University and joined the research group of Professor Yoshida. In 1999, he received Nissan Chemical Industries Award in Synthetic Organic Chemistry, Japan. His research interests include (1) the development of new reagents and methods for organic synthesis, with emphasis on transition metal catalysis, (2) aqueous organic and organometallic reactions, (3) strategic separation in organic synthesis, and (4) strategic integration of metal-catalyzed reaction for diversity-oriented synthesis 